\title{
High concentration and high dose of disinfectants and antibiotics used during the COVID-19 pandemic threaten human health
}

\author{
Zhongli Chen, Jinsong Guo, Yanxue Jiang and Ying Shao* (1)
}

\begin{abstract}
The issue of coronavirus disease 2019 (COVID-19), caused by severe acute respiratory syndrome coronavirus-2 (SARSCoV-2), has created enormous threat to global health. In an effort to contain the spread of COVID-19, a huge amount of disinfectants and antibiotics have been utilized on public health. Accordingly, the concentration of disinfectants and antibiotics is increasing rapidly in various environments, including wastewater, surface waters, soils and sediments. The aims of this study were to analyze the potential ecological environment impacts of disinfectants and antibiotics by summarizing their utilization, environmental occurrence, distribution and toxicity. The paper highlights the promoting effects of disinfectants and antibiotics on antibiotic resistance genes (ARGs) and even antibiotic resistant bacteria (ARB). The scientific evidences indicate that the high concentration and high dose of disinfectants and antibiotics promote the evolution toward antimicrobial resistance through horizontal gene transformation and vertical gene transformation, which threaten human health. Further concerns should be focused more on the enrichment, bioaccumulation and biomagnification of disinfectants, antibiotics, antibiotic resistance genes (ARGs) and even antibiotic resistant bacteria (ARB) in human bodies.
\end{abstract}

\section{Introduction}

As the coronavirus disease 2019 (COVID-19) epidemic worsens, various disinfectants and pharmaceuticals have been actively used to control the spread of the virus. Disinfectants, such as alcohols, chlorine, formaldehyde, glutaraldehyde, ortho-phthalaldehyde, hydrogen peroxide, iodophors, peracetic acid, phenolics, and quaternary ammonium compounds were recommended to use alone or in combinations on public health by authorities. The Chinese Center for Disease Control and Prevention (China CDC), United States Environmental Protection Agency (US EPA) and World Health Organization (WHO) successively released the guidance for

\footnotetext{
${ }^{*}$ Correspondence: ying.shao@cqu.edu.cn

Key Laboratory of the Three Gorges Reservoir Eco-Environment,

Chongqing University, Chongqing 400045, People's Republic of China
}

disinfectant utilization to against the virus, while the lack of necessary training program for public could raise the adverse effects of disinfectant on human health [1]. Besides disinfectants, mass production and considerable pharmaceuticals, in particular antibiotics, are applied to treat bacterial infections. For instance, in the United States alone, over 250 million antibiotic prescriptions are written annually. In China, 96 million kg antibiotics were used in 2007. These antibiotics cannot be completely metabolized or eliminated in the body, and $30-90 \%$ of which are excreted unchanged into the waste system [2]. Traditional wastewater treatment processes can only remove $20-80 \%$ of pharmaceuticals and their metabolites [3]. Therefore, either directly or indirectly, these disinfectants and antibiotics will eventually be emitted in environments. Accordingly, disinfectants and antibiotics were frequently detected in surface waters, ground 
waters, soils, sediments and wetlands, with the amounts up to $1 \mathrm{mg} / \mathrm{L}$, the environmental impacts therefore become a worldwide concern [4].

In the times of COVID-19 panic, disinfectants and antibiotics were overused for the coronavirus disease control and treatment, since the effective treatment measures and medications are not yet determined. Until 2020 March, China has dispensed at least 2000 tons of disinfectants in the city of Wuhan alone (Fig. 1) [5]. Even though the novel coronavirus is virus, and antibiotics cannot been used for treatment the disease of COVID19 directly, numerous antibiotics were widely utilized to resist the COVID-19-induced inflammation and other disease. These increasing use and misuse will definitely increase the concentration and dose of disinfectants and antibiotics in environments. Thus, can the high concentration and high dose of disinfectants and antibiotics during the COVID-19 pandemic lead to more stress on ecological safety and human health?

\section{Toxicity}

Considering that disinfectants and antibiotics are designed for the treatment of bacterial infections, it is reasonable to assume that non-target environmental organism and/or microorganism are more likely to be affected due to non-therapeutic exposure [6]. Many environmental studies hence focus on the occurrence of disinfectants by-products (DBPs) and antibiotics residuals in diverse environments and their toxic effects on various organisms [7-9]. DBPs and antibiotics in surface waters and sewerage treatment plant effluents/wastewaters are generally measured at concentrations ranging between 0.01 and $1.0 \mu \mathrm{g} / \mathrm{L}$ [10]. Many DBPs were proved to inhibit the growth of freshwater algae and duckweeds

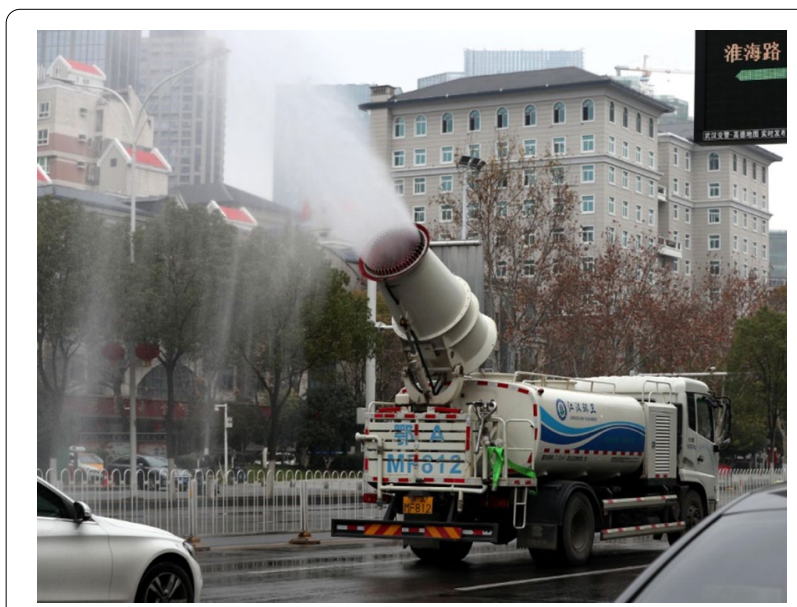

Fig. 1 Disinfection and sterilization in Wuhan, China. The figure was cited from the China Daily website on April 13, 2020 by disturbing the function of photosynthesis through inhibition and interference of chloroplast metabolism at environmental concentrations [10]. Most of the emerging DBPs were found to induce oxidative stress, DNA damage, and activate DNA repair system at environmental concentrations [11]. Chronic toxicological studies pointed that exposure to DBPs may induce genotoxicity, cytotoxicity, asthma, skin rashes, bladder and colon cancer in humans [12]. The frequently detected DBPs of trichloromethane, dibromochloromethane, bromodichloromethane, tribromomethane, dichloroacetonitrile and dibromoacetonitrile have hence recommended specific maximum values at $200,100,60,100,20$, and $70 \mu \mathrm{g} / \mathrm{L}$, respectively, in the WHO Guidelines [13]. Antibiotics can affect prokaryotic cells by inhibition of cell envelope synthesis, protein synthesis and nucleic acid (DNA/RNA) synthesis [10]. Environmental exposures of antibiotics, such as diclofenac, erythromycin, fluoxetine and carbamazepine, caused gill alterations, renal lesions and oxidative DNA damage in rainbow trout, delay in Zebrafish hatching, growth inhibition in cyanobacteria and green algae, neurotoxicity and behavioral changes [14]. It is noted that that the more frequent home use of disinfectants was associated with dysbiosis in infant gut microbiota, which may lead to childhood overweight and obesity [15]. Therefore, the environmental risk assessment is required for a medicine if the predicted environmental concentration exceeds $10 \mathrm{ng} / \mathrm{L}$ in Europe [16].

\section{Antimicrobial resistance evolution}

Disinfectant by-products and antibiotic residues permanently existed in diverse environments, which can persistently promote bacterial evolution toward antimicrobial resistance (AMR). Bacteria, only carrying antibiotic resistance genes (ARGs), can survive and persist in these contaminated environments. A disinfection byproducts study reported that disinfection by-products can select strain with high-level resistance via broadly conserved cellular functions and pathways at the minimal inhibitory concentrations [17].

In fact, ARGs and antibiotic resistant bacteria (ARB) can be target selected in disinfectants and antibiotics contaminated environments.[18]. The ARGs spread among bacteria, namely horizontal gene transformation (HGT), which induced the enrichment effects of ARGs in ARB through the uptake of naked DNA and mobile genetic elements such as plasmids, transposons, integrons, gene cassettes, and bacteriophages [17, 19]. Expansions in the diversity and abundance of ARGs were hence presented in water, soil and air, which may disturb the normal microflora. Emergence of resistance amongst bacteria in the normal flora and distribution of resistant genes can contribute to an increased load of resistant, 
potentially pathogenic microorganisms and reduce the colonization resistance leading to overgrowth of exogenic pathogens [20]. New ARB, such as the COVID-19, could be a result of ARGs enrichment and microflora disturbance, and it hence increased and spread rapidly all over the world in recent years. Conversely, the huge amounts of ARGs and ARB would promote the evolution of microbial structure through ecological niches occupation, which will enhance the pressure of target selection. Consequently, it may induce the imbalance of microbial ecosystem.

Besides HGT, ARGs and ARB can also be transferred from environments or microorganisms to higher trophic levels through drinking water, food and respiration [21]. Human health studies reported that the ARGs and ARB were frequently detected in animal and human gut. A dietary exposure study reported that the number and abundance of ARGs significantly increased in the collembolan gut microbiome after antibiotic exposure for 14 days [22]. Many clinically relevant ARGs are found to originate from non-pathogenic environmental bacteria. These ARGs and ARB lead to the reduction of the effectiveness of antimicrobial drugs during clinical practice, and finally will implicate human health. It is estimated that AMR causes 700,000 deaths annually worldwide. If no proper action is taken, these number could grow to 10 million per year by 2050 [23]. The WHO hence issued in 2017 that AMR has become a critical global public health issue of this century.

\section{Conclusion}

COVID-19 has threatened the global health remarkably. High concentration and high dose of disinfectants and antibiotics used during the COVID-19 pandemic, which entered into environments, are definitely accelerating the target selection of AMR in environments [24]. HGT among bacteria increases the enrichment of ARGs in ARB. Vertical gene transformation through food chain put the trophic level organisms in a high risk of AMR bioaccumulation and biomagnification. Human beings, at the top of the food chain, are actually exposed in a mixture of high level of disinfectants, antibiotics, ARGs and ARB. Environment studies focusing only on the damage of chemicals or AMR with ignoring the mixture effects is not enough. Further researches have to pay more attention on the enrichment, bioaccumulation and biomagnification of disinfectants, antibiotics, ARGs and even ARB in human bodies. The rapid detection technologies for COVID-19 have to be accelerated development, which could provide useful information on guiding the usage of disinfectants and antibiotics [25]. Management on solid and liquid waste is required to update for adaptation the changes of lifestyle during the COVID-19 outbreak, including developing flexible waste treatment plans and the corresponding training, and establishment longerterm systematic assessments [26, 27]. Ecological techniques such as constructed wetlands which can remove disinfectants and antibiotics by sunlight photo degradation, biodegradation and adsorption should be applied for ameliorating the impacts of disinfectants and antibiotics in aquatic environments [28].

\section{Abbreviations \\ COVID-19: Coronavirus disease 2019; SARS-CoV-2: Severe acute respiratory syndrome coronavirus-2; CDC: The Chinese Center for Disease Control and Prevention; EPA: United States Environmental Protection Agency; WHO: World Health Organization; DBPs: Disinfectants by-products; AMR: Antimicrobial resistance; ARGs: Antibiotic resistance genes; ARB: Antibiotic resistant bacteria; HGT: Horizontal gene transformation.}

\section{Acknowledgements}

We appreciate the contribution of all participants.

\section{Authors' contributions}

YS was responsible for the general design of the review and wrote the first draft of the manuscript. ZLC, YXJ drafted the manuscript; JSG contributed to support the writing of the manuscript. All authors read and approved the final manuscript.

\section{Funding}

This work was supported by the Fundamental Research Funds for the Central Universities (No. 2020CDJQY-A016; No. 2019CDYGYB028) and the Vebture \& Innovation Support Program for Chongqing Overseas Retureness (No. cx2019110; No. cx2020064).

\section{Availability of data and materials}

The datasets used and/or analyzed during the current study are available from the corresponding author on reasonable request.

\section{Ethics approval and consent to participate} Not applicable.

\section{Consent for publication}

All authors agreed to publish the paper.

\section{Competing interests}

The authors declare that they have no competing interests.

Received: 30 October 2020 Accepted: 21 January 2021

Published online: 29 January 2021

\section{References}

1. Dindarloo K, Aghamolaei T, Ghanbarnejad A, Turki H, Hosmmayeh H, Pasalari H, Ghaffari HR (2020) Pattern of disinfectants use and their adverse effects on the consumers after COVID-19 outbreak. J Environ Health Sci Eng. https://doi.org/10.1007/s40201-020-00548-y

2. Watkinson AJ, Murby EJ, Costanzo SD (2007) Removal of antibiotics in conventional and advanced wastewater treatment: Implications for environmental discharge and wastewater recycling. Water Res 41(18):4164-4176

3. Kovalova L, Siegrist H, Singer H, Wittmer A, McArdell CS (2012) Hospital wastewater treatment by membrane bioreactor: performance and efficiency for organic micropollutant elimination. Environ Sci Technol 46(3):1536-1545

4. Chatterjee A (2020) Use of hypochlorite solution as disinfectant during COVID-19 outbreak in India: from the perspective of human health and atmospheric chemistry. Aerosol Air Quality Res 20(7):1516-1519 
5. Zhang H, Tang WZ, Chen YS, Yin W (2020) Disinfection threatens aquatic ecosystems. Science 368(6487):146-147

6. LV L, Jiang T, Zhang SH, Yu X (2014) Exposure to mutagenic disinfection byproducts leads to increase of antibiotic resistance in Pseudomonas aeruginosa. Environ Sci Technol 48(14):8188-8195

7. Perveen S, Hashmi I, Khan R (2019) Evaluation of genotoxicity and hematological effects in common carp (Cyprinus carpio) induced by disinfection by-products. J Water Health 17(5):762-776

8. Macedo LPR, Dornelas ASP, Vieira MM, de Jesus Ferreira JS, Sarmnto RA, Cavallini GS (2019) Comparative ecotoxicological evaluation of peracetic acid and the active chlorine of calcium hypochlorite: use of Dugesia tigrina as a bioindicator of environmental pollution. Chemosphere 233:273-281

9. Chhetri RK, Baun A, Andersen HR (2019) Acute toxicity and risk evaluation of the CSO disinfectants performic acid, peracetic acid, chlorine dioxide and their by-products hydrogen peroxide and chlorite. Sci Total Environ 677:1-8

10. Le Page G, Gunnarsson L, Snape J, Tyler CR (2017) Integrating human and environmental health in antibiotic risk assessment: a critical analysis of protection goals, species sensitivity and antimicrobial resistance. Environ Int 109:155-169

11. Ma LP, Li AD, Yin $X L$, Zhang $T$ (2017) The prevalence of integrons as the carrier of antibiotic resistance genes in natural and man-made environments. Environ Sci Technol 51(10):5721-5728

12. Chaves RS, Guerreiro CS, Cardoso VV, Benoliel MJ, Santons MM (2020) Toxicological assessment of seven unregulated drinking water disinfection by-products (DBPs) using the zebrafish embryo bioassay. Sci Total Environ 742:140522-140522

13. Li Y, Jiang JY, Li WX, Zhu XH, Zhang XR, Jiang F (2020) Volatile DBPs contributed marginally to the developmental toxicity of drinking water DBP mixtures against Platynereis dumerilii. Chemosphere 252:9

14. Khan HK, Rehman MYA, Malik RN (2020) Fate and toxicity of pharmaceuticals in water environment: an insight on their occurrence in South Asia. J Environ Manage 271:111030-111030

15. Ejtahed H-S, Hasani-Ranjbar S, Siadat SD, Larijani B (2020) The most important challenges ahead of microbiome pattern in the post era of the COVID-19 pandemic. J Diabetes Metabolic Disord. https://doi. org/10.1007/s40200-020-00579-0

16. EMA (2006) Guideline on the environmental risk assessment of medicinal products for human use (CPMP/SWP/4447/00 Corr 2)

17. Mantilla-Calderon D, Plewa MJ, Michoud G, Fodelianakis S, Daffonchio D, Hong PY (2019) Water disinfection byproducts increase natural transformation rates of environmental DNA in Acinetobacter baylyi ADP1. Environ Sci Technol 53(11):6520-6528

18. Wanja DW, Mbuthia PG, Waruiru RM, Bebora LC, Ngowi HA, Nyaga PN (2020) Antibiotic and disinfectant susceptibility patterns of bacteria isolated from farmed fish in Kirinyaga County Kenya. Int J Microbiol 2020:8. https://doi.org/10.1155/2020/8897338

19. Nwosu VC (2001) Antibiotic resistance with particular reference to soil microorganisms. Res Microbiol 152(5):421-430

20. Rashid M-U, Weintraub A, Nord CE (2012) Effect of new antimicrobial agents on the ecological balance of human microflora. Anaerobe 18(2):249-253

21. Felis E, Kalka J, Sochachki A, Kowalska K, Bajkacz S, Harnisz M, Korzeniewska E (2020) Antimicrobial pharmaceuticals in the aquatic environment-occurrence and environmental implications. Eur J Pharmacol. 866:172813

22. Zhu D, An XL, Chen QL, Yang XR, Christie P, Ke X, Wu LH, Zhu YG (2018) Antibiotics disturb the microbiome and increase the incidence of resistance genes in the gut of a common soil Collembolan. Environ Sci Technol 52(5):3081-3090

23. Roope LSJ, Smith RD, Pouwels KB, Buchanan J, Abel L, Eibich P, Butler CC, Tan PS, Walker AS, Robotham JV, Wordsworth S (2019) The challenge of antimicrobial resistance: what economics can contribute. Science 364(6435):4679. https://doi.org/10.1126/science.aau4679

24. Bandyopadhyay S, Samanta I (2020) Antimicrobial resistance in agri-food chain and companion animals as a re-emerging menace in post-COVID epoch: low-and middle-income countries perspective and mitigation strategies. Front Veterin Sci 7:620. https://doi.org/10.3389/fvets 2020.00620

25. Gao J, Quan L (2020) Current status of diagnostic testing for SARS-CoV-2 infection and future developments: a review. Med Sci Monit 26:e928552

26. Ragazzi M, Rada EC, Schiavon M (2020) Municipal solid waste management during the SARS-COV-2 outbreak and lockdown ease: lessons from Italy. Sci Total Environ 745:141159

27. Fan YV, Jiang P, Hemzal M, Klemeš JJ (2021) An update of COVID-19 influence on waste management. Sci Total Environ 754:142014

28. Choi YJ, Kim LH, Zoh KD (2016) Removal characteristics and mechanism of antibiotics using constructed wetlands. Ecol Eng 91:85-92

\section{Publisher's Note}

Springer Nature remains neutral with regard to jurisdictional claims in published maps and institutional affiliations.

\section{Submit your manuscript to a SpringerOpen ${ }^{\circ}$ journal and benefit from:}

- Convenient online submission

- Rigorous peer review

- Open access: articles freely available online

- High visibility within the field

Retaining the copyright to your article

Submit your next manuscript at springeropen.com 